\title{
Involvement of Autophagic Pathway in the Progression of Retinal Degeneration in a Mouse Model of Diabetes
}

\author{
Ilaria Piano ${ }^{1 *}$, Elena Novelli ${ }^{2}$, Luca Della Santina ${ }^{1}$, Enrica Stretto ${ }^{2}$, Luigi Cervetto ${ }^{1}$ \\ and Claudia Gargini ${ }^{1}$
}

${ }^{1}$ Department of Pharmacy, University of Pisa, Pisa, Italy, ${ }^{2}$ National Research Council (CNR), Neuroscience Institute, Pisa, Italy

OPEN ACCESS

Edited by:

Francesco Moccia

University of Pavia, Italy

Reviewed by:

Daniela Tropea,

Trinity College Dublin, Ireland Yasushi Kitaoka,

St. Marianna University School of

Medicine, Japan

*Correspondence:

Ilaria Piano

ilapi@hotmail.it

Received: 09 December 2015 Accepted: 08 February 2016 Published: 19 February 2016

Citation:

Piano I, Novelli E, Della Santina L, Strettoi $E$, Cervetto $L$ and Gargini $C$ (2016) Involvement of Autophagic Pathway in the Progression of Retinal

Degeneration in a Mouse Model

of Diabetes.

Front. Cell. Neurosci. 10:42.

doi: 10.3389/fncel.2016.00042
The notion that diabetic retinopathy (DR) is essentially a micro-vascular disease has been recently challenged by studies reporting that vascular changes are preceded by signs of damage and loss of retinal neurons. As to the mode by which neuronal death occurs, the evidence that apoptosis is the main cause of neuronal loss is far from compelling. The objective of this study was to investigate these controversies in a mouse model of streptozotocin (STZ) induced diabetes. Starting from 8 weeks after diabetes induction there was loss of rod but not of cone photoreceptors, together with reduced thickness of the outer and inner synaptic layers. Correspondingly, rhodopsin expression was downregulated and the scotopic electroretinogram (ERG) is suppressed. In contrast, cone opsin expression and photopic ERG response were not affected. Suppression of the scotopic ERG preceded morphological changes as well as any detectable sign of vascular alteration. Only sparse apoptotic figures were detected by terminal deoxynucleotidyl transferase dUTP nick end labeling (TUNEL) assay and glia was not activated. The physiological autophagy flow was altered instead, as seen by increased LC3 immunostaining at the level of outer plexiform layer (OPL) and upregulation of the autophagic proteins Beclin-1 and Atg5. Collectively, our results show that the streptozotocin induced DR in mouse initiates with a functional loss of the rod visual pathway. The pathogenic pathways leading to cell death develop with the initial dysregulation of autophagy well before the appearance of signs of vascular damage and without strong involvement of apoptosis.

Keywords: diabetic retinopathy, mouse model, retinal damage, photoreceptors, autophagy

\section{INTRODUCTION}

Chronic exposure to hyperglycemia triggers a chain of biochemical and functional processes leading to vascular damage and to a series of central and peripheral neuropathies. The diabetic retinopathy (DR) is the one of the most common complications of diabetes (Antonetti et al., 2006; Kaul et al., 2013; Blake and Trounce, 2014) and a leading cause of blindness worldwide (Cheung et al., 2010). The notion that DR is essentially a microvascular disease has been recently challenged by several studies reporting that the vascular changes are preceded by signs of functional impairment and loss of neural retinal cells (Zeng et al., 2000; Martin et al., 2004; Bearse et al., 2006; Gaucher et al., 2007). Furthermore, the mechanisms of photoreceptors death have not been conclusively established. 
This lack of understanding has seriously limited the therapeutic options available for the ophthalmologist and there is a need to identify the pathways that initiate retinal cell damage and drive progression to overt retinopathy. Apoptotic pathways are involved in the death of ganglion cells (Martin et al., 2004; Barber et al., 2005), while cell death in the outer retina remains unexplained. Apoptosis in diabetes was observed in human retinas as well as in animal models of DR (Abu-El-Asrar et al., 2004; Barber et al., 2005), causing retinal thinning in rats starting 6 months after diabetes induction (Park et al., 2003). It must be pointed out, however, that early changes in outer retinal neurons occur well before the appearance of apoptotic figures (Énzsöly et al., 2014), with evidence supporting a role for autophagy in the pathophysiology of type-1 diabetes from a variety of tissues (Gonzalez et al., 2011).

The objective of this study was to investigate the sequence of changes leading to retinal damage in a mouse model of type-1 streptozotocin (STZ) induced diabetes (Jo et al., 2013). Our results showed that specific changes in function, morphology and biochemistry develop within 12 weeks after diabetes induction, consisting in the suppression of scotopic electroretinogram (ERG) response, rods loss and reduction of retinal thickness. All these changes preceded any detectable vascular alteration, apoptotic figures were rare and glia did not activate. On the other hand, specific tests reveal a marked up-regulation of autophagic processes suggesting that the autophagic pathway is involved in the initial damage of the visual neurons of the rod pathway.

\section{MATERIALS AND METHODS}

\section{Animals}

C57BL/6J mice (Jackson Laboratories, Sacramento, CA, USA), were housed in $12 \mathrm{~h}$ light/dark cycle with illumination levels below 60 lux. Diabetes was induced at P30 by single i.p. injection of $150 \mathrm{mg} / \mathrm{Kg}$ STZ, (Sigma-Aldrich, St. Louis, MO, USA; Wang et al., 2010). The blood glucose concentration was measured before each experiment from the tail vein using a One Touch Ultra Easy device (LifeScan, Roma, Italy). Hyperglycemia was defined as blood glucose $>16.7 \mathrm{mmol} / \mathrm{L}, 48 \mathrm{~h}$ after STZ injection. Age-matched control mice received a single i.p. injection of vehicle (citrate buffer, $\mathrm{pH}$ 4.5). Mice were no treated with insulin. All mice were then tested at 4, 8 and 12 weeks post-injection.

All experiments were carried out in accordance to the ARVO statement for the use of animals in Ophthalmic and Vision Research. Animal protocol was approved by the Animal Care Committee of the University of Pisa, Italy (Protocol. N.4886, April 4th, 2011). For all procedures, mice were anesthetized with Urethane 20\% (100 $\mu \mathrm{l} / 10 \mathrm{~g}$, Sigma-Aldrich).

\section{Immunohistochemistry}

Retinal section preparation has been previously described in detail (Della Santina et al., 2012). Sections were washed $3 \times 10 \mathrm{~min}$ in phosphate buffered saline (PBS), then incubated $45 \mathrm{~min}$ in blocking solution (1\% bovine serum albumin; BSA, $0.3 \%$ Triton-X100 in PBS). Sections were incubated overnight at $4^{\circ} \mathrm{C}$ with primary antibodies (Table 1). Sections were then washed $3 \times 10 \mathrm{~min}$ in PBS and incubated with secondary antibodies (Table 1) for $2 \mathrm{~h}$ at room temperature. Nuclear staining was obtained with propidium iodide. Confocal images were obtained with a Leica TCS-SL microscope (Leica Microsystem, Wetzlar, Germany).

\section{TUNEL Assay}

Terminal deoxynucleotidyl transferase dUTP nick end labeling (TUNEL) staining was performed according to the manufacturer's protocols for frozen sections (Promega, Milan, Italy). Sections pre-incubated with DNase were used as positive control. Sections from a retinal degeneration mouse (rd10 mutant; Gargini et al., 2007) known to contain apoptotic bodies were also used as positive controls. Nuclear staining was obtained with Hoechst (Life Technologies, Carlsbad, CA, USA). Images were taken with a Zeiss Apotome (Carl Zeiss, Oberkochen, Germany) microscope using a $16 \times$ lens. Individual images were digitally stitched together to reconstruct the entire section using Photoshop (Adobe, San Jose, CA, USA).

\section{Retinal Thickness Analysis}

Cryosections where cell nuclei were labeled by $1 \mathrm{mM}$ bisbenzimide were used for analysis. Images were acquired on a Zeiss Axiophot (Carl Zeiss) microscope using a $40 \times$ dry objective. Images were taken from dorsal and ventral retina, at distances between 250 and $500 \mu \mathrm{m}$ (central retina) and higher than $500 \mu \mathrm{m}$ (peripheral retina) from the optic nerve head.

For each section, eight different locations (field size: $290 \times$ $320 \mu \mathrm{m}$ ) were measured and averaged. At least three sections per each retina were measured.

\section{Blood Vessels}

The blood vessel complexity was estimated, on retinal whole mounts prepared as described elsewhere (Barone et al., 2012). Blood vessels were stained by incubating retinal whole mount for 3 days in FITC-conjugated Griffonia Simplicifolia (1:50 in artificial cerebro-spinal fluid and $0.1 \%$ Triton X-100, Sigma Aldrich) and examined with a Leica TCS SL confocal microscope. For each retina eight regularly spaced fields were sampled (937.5 $\times 937.5 \mu \mathrm{m}$ in size). Sampled fields systematically covered central and peripheral areas of the four quadrants (Dorsal, Ventral, Nasal and Temporal). Within each field, three blood vessel plexa (superficial, intermediate and deep), were individually acquired along the $z$-axis at $1 \mu \mathrm{m}$ intervals. Average intensity projection images of each plexa were used for morphometric analysis.

To calculate vascular area, the auto-threshold function of Metamorph software (Molecular Devices, LLC, USA) was chosen to identify vessels from background. Data from all quadrants of each retina were averaged, then values of each retina were used for plotting and statistical comparison. To calculate vascular complexity, each image was binarized using the Fiji's threshold function (Schindelin et al., 2012), then intersected with a $50 \times 50 \mu \mathrm{m}$ mesh grid. Finally, intersection points in the resulting image were counted using the Fiji plugin " $3 \mathrm{D}$ Objects counter" (Bolte and Cordelières, 2006) and expressed as number 


\begin{tabular}{|c|c|c|c|c|}
\hline & Host & Dilution & Supply & Application \\
\hline \multicolumn{5}{|l|}{ Primary antibody } \\
\hline Protein Kinase $\mathrm{C} \alpha$ & Mouse & $1: 100$ & Sigma-Aldrich & $\mathrm{IF}^{*}$ \\
\hline PSD95 & Mouse & $1: 1000$ & Millipore & $\mathrm{IF}^{*}$ \\
\hline GFAP & Rabbit & $1: 100$ & Sigma-Aldrich & $\mathrm{IF}^{*}$ \\
\hline LC3A & Rabbit & $1: 200$ & Cell Signaling & $\mathrm{IF}^{*}, \mathrm{WB}^{\dagger}$ \\
\hline Rhodopsin & Mouse & $1: 1000$ & Sigma-Aldrich & $\mathrm{WB}^{\dagger}$ \\
\hline Red/green cone opsin & Rabbit & $1: 1000$ & Santa Cruz Biotechnology & $\mathrm{WB}^{\dagger}$ \\
\hline Blue cone opsin & Rabbit & $1: 1000$ & Santa Cruz Biotechnology & $\mathrm{WB}^{\dagger}$ \\
\hline Caspase-3 & Rabbit & $1: 100$ & Santa Cruz Biotechnology & $\mathrm{WB}^{\dagger}$ \\
\hline Beclin-1 & Rabbit & $1: 1000$ & Cell Signaling & $\mathrm{WB}^{\dagger}$ \\
\hline Atg5 & Rabbit & $1: 1000$ & Cell Signaling & $\mathrm{WB}^{\dagger}$ \\
\hline$\beta$-Actin & Mouse & $1: 2000$ & Sigma-Aldrich & $W^{\dagger}$ \\
\hline GAPDH & Rabbit & $1: 5000$ & Sigma-Aldrich & $\mathrm{WB}^{\dagger}$ \\
\hline \multicolumn{5}{|l|}{ Secondary Antibody } \\
\hline Anti-mouse Alexa Fluo 488 & Goat & $1: 500$ & Molecular Probes & $\mathrm{IF}^{*}$ \\
\hline Anti-goat Alexa Fluo 488 & Donkey & $1: 500$ & Molecular Probes & $\mathrm{IF}^{*}$ \\
\hline Anti-mouse Rhodamin RedX & Goat & 1:1000 & Jackson Immuno Research & $\mathrm{IF}^{*}$ \\
\hline Anti-rabbit Rhodamin RedX & Goat & 1:1000 & Jackson Immuno Research & $\mathrm{IF}^{*}$ \\
\hline Anti-mouse HRP & Goat & $1: 10000$ & Millipore & $\mathrm{WB}^{\dagger}$ \\
\hline Anti-rabbit HRP & Goat & $1: 10000$ & Millipore & $\mathrm{WB}^{\dagger}$ \\
\hline Anti-rabbit HRP & Goat & $1: 2000$ & Cell Signaling & $\mathrm{WB}^{\dagger}$ \\
\hline
\end{tabular}

*IF: Immunofluorescence; ${ }^{\dagger} W B$ : Western blot.

of intersections per $\mathrm{mm}^{2}$. Data from all quadrants of each retina were averaged, then values of each retina were used for plotting and statistical comparison.

\section{Electroretinogram (ERG)}

The general procedure for animal preparation, anesthesia, ERG recording, light stimulation and data analysis has been previously described in detail (Della Santina et al., 2012). Following 4, 8 and 12 weeks of diabetes, control and diabetic mice were tested for scotopic and photopic ERG. For scotopic ERG recordings, mice were presented with a single flash of increasing intensity $\left(2.19 \times 10^{-4}\right.$ to $83.7 \mathrm{~cd}^{*} \mathrm{~s} / \mathrm{m}^{2}, 0.6 \log$ units steps), each repeated five times, with an inter-stimulus interval ranging from $20 \mathrm{~s}$ for dim flashes to $1 \mathrm{~min}$ for the brightest flashes. Five ERG traces at each flash luminance were averaged. Isolated cone components were obtained by superimposing the test flashes (0.016 to $\left.377 \mathrm{~cd}^{*} \mathrm{~s} / \mathrm{m}^{2}\right)$, on a steady background of saturating intensity for rods $\left(30 \mathrm{~cd} / \mathrm{m}^{2}\right)$ after at least $15 \mathrm{~min}$ from background onset. Oscillatory potentials (OPs) were also measured in both scotopic and photopic conditions. OPs were extracted digitally by using a fifth-order Butterworth filter as described by others (Hancock and Kraft, 2004; Lei et al., 2006). Peak amplitude and implicit time of each OP (OP1-OP4) were measured.

\section{Soluble and Insoluble Protein Separation and Western Blot Analysis}

Detergent-insoluble protein aggregates were isolated according to Johnston et al. (1998). Retinas were lysed in $50 \mu \mathrm{l}$ immunoprecipitation buffer (IPB, $10 \mathrm{mM}$ Tris- $\mathrm{HCl}, 5 \mathrm{mM}$ EDTA, 1\% NP-40, 0.5\% Na-deoxycholate, $150 \mathrm{mM} \mathrm{NaCl}$, protease inhibitors, $\mathrm{pH}=7.5$ ) and incubated on ice for $30 \mathrm{~min}$. Lysates were centrifuged for $15 \mathrm{~min}$ at $13,000 \mathrm{rpm}$ then supernatants were collected (soluble proteins). The insoluble material was incubated in $50 \mu \mathrm{l}$ of $10 \mathrm{mM}$ Tris- $\mathrm{HCl}, 1 \%$ SDS for $10 \mathrm{~min}$ at room temperature. Following to the addiction of $50 \mu \mathrm{l}$ $\mathrm{IPB}$, pellets were sonicated for $20 \mathrm{~s}$ and the total protein content was quantified by Bradford method.

To assess rhodopsin, cone-opsin and apoptosis markers, $50 \mu \mathrm{g}$ of soluble protein were electrophoresed on a sodium dodecyl sulfate (SDS)-polyacrylamide gel (12\% for opsins, $15 \%$ for apoptosis markers). Proteins were transferred to polyvinylidene fluoride membrane (Immobilon-P Transfer membrane $0.45 \mu \mathrm{m}$, Millipore, Darmstadt, Germany) using a transfer buffer (25 mM Tris- $\mathrm{HCl}, \mathrm{pH}=8.3,192 \mathrm{mM}$ glycine, $20 \%$ methanol). To detect the presence of autophagy markers, $20 \mu \mathrm{g}$ of insoluble proteins were loaded on $4-20 \%$ precast SDS-polyacrilamide gels. Proteins were blotted on nitrocellulose membrane (Sigma-Aldrich, $0.22 \mu \mathrm{m}$ pore size).

For all cases, the protein blot was blocked for $1 \mathrm{~h}$ at room temperature with blocking solution (5\% non-fat dried milk and $0.1 \%$ Tween-20 in $20 \mathrm{mM}$ Tris- $\mathrm{HCl}, 500 \mathrm{mM} \mathrm{NaCl}$, $\mathrm{pH}=8$ ). The membrane was then incubated overnight at $4^{\circ} \mathrm{C}$ with primary antibodies (Table 1) diluted in blocking buffer. Horseradish peroxidase (HRP)-conjugated secondary antibodies (Table 1) were incubated $2 \mathrm{~h}$ at room temperature. Bands were visualized using a chemo luminescence kit (Santa Cruz) and quantified by optical densitometry. Images were acquired using ImageQuant LAS4010 (GE Healthcare, Buckingamshire, $\mathrm{UK})$. On the same blots, protein contents were normalized to the amounts of $\beta$-actin or Glyceraldehyde 3-phosphate dehydrogenase (GAPDH, Sigma-Aldrich).

\section{Statistical Analysis}

Statistical comparisons for ERG, western blot, and blood vessel analysis were performed with analysis of variance (ANOVA) 
one-way or two-way test followed by Bonferroni-corrected t-test using Origin Lab 8.0 software (Microcal, Northampton, MA, USA).

\section{RESULTS}

Three groups of diabetic mice were separately tested 4,8 and 12 weeks after a single dose of STZ i.p. Littermate mice that received a single dose of only the vehicle served as control groups. Table $\mathbf{2}$ shows the average serum glucose levels for all experimental animals at 4, 8 and 12 weeks following induction of diabetes. The starting body weight of control and diabetic mice was not different $(P=0.73$, ANOVA). The weight of control mice increased constantly with time $(+1 \mathrm{~g} /$ week $)$, while that of diabetics either remained constant or decreased slightly $(-0.56 \mathrm{~g} /$ week $)$.

We recorded the ERG response in control and diabetic mice at different times following STZ injection. Figure 1A shows representative scotopic ERG responses to flashes of light of increasing luminance at different times of the disease progression. Traces at the bottom of Figure 1A are the OPs isolated from responses to the brightest flash. As shown in Figure 1B, the amplitude of the scotopic b-wave was reduced starting from 4 weeks after diabetes induction (Figure 1B, left plot, $P=8.8 \times 10^{-16}$, two way ANOVA) and remained significantly lower than in control mice at all ages under examination (Figure 1B, histograms). In parallel, scotopic a-wave amplitude in diabetic mice was significantly reduced compared to control mice starting from 4 weeks after induction of diabetes (Figure 1C, $P=0.02$, two-way ANOVA). Only a small reduction in time of the ERG amplitude was observed in the control groups across time while, at any given time point, significant difference of the scotopic ERG amplitude was observed between diabetic and control mice.

Amplitude and kinetics of the OPs (OP1, 2 and 3) was also affected in diabetic mice starting 4 weeks after injection of STZ: the amplitude decreased and implicit time increased in diabetic mice compared to control (Figure 1D, OP1: $P=0.22$; OP2: $P=0.12$; OP3: $P=0.07$; OP4: $P=0.093$, $t$-test). In order to investigate where the functional changes originate, we analyzed the b-wave vs. a-wave ratio. The average ratio remained constant at all time points analyzed
(4 weeks: $16.05 \pm 4.56$; 8 weeks: $11.27 \pm 3.00 ; 12$ weeks: $12.58 \pm 3.67$; ANOVA one-way $P=0.69$ ), suggesting that the early functional changes experienced by diabetic mice can be explained primarily by the damage inflicted to their rod photoreceptors.

We also recorded photopic ERG responses from the same animals (Figure 2). Figure $\mathbf{2 A}$ shows representative photopic ERG waveforms, and relative OPs, at increasing light intensity levels for mice 12 weeks from diabetes induction. As shown in Figure 2B, the amplitude of the photopic b-wave did not change up to 12 weeks following diabetes induction compared to control ( $P=0.16, t$-test). The amplitude and kinetics of the photopic OPs were not altered in diabetic mice compared to controls (Figure 2C). These results indicate that outer retina changes in diabetic mice mainly concern the rod pathway. It must be emphasized that impaired functionality always preceded the morphological signs of damage.

The panels of Figure 3A show a vertical section of retinas from control (12 weeks post vehicle-injections) and diabetic mice (4, 8 and 12 weeks post STZ-injections) where reduction in the total thickness of the retina can be observed. Furthermore, specific staining of rod-bipolar cells ( $\mathrm{PKC} \alpha$, green) shows that, starting from 8 weeks after induction of diabetes, there was a strong regression of dendrites, axons and synaptic terminals. In the central retina, thickness was reduced 4 weeks after diabetes induction for the outer plexiform layer (OPL) and after 8 weeks also for the inner plexiform layer (IPL, Figure 3B, lower panel). On the other hand, thickness of synaptic layers in the peripheral retina decreased since 8 weeks from STZ injection (Figure 3B, upper panel), supporting a center-to-periphery gradient of synaptic degeneration. Because no significant differences were observed among animals of the control groups all vehicle measurements are shown in Figure $3 \mathbf{B}$ as pooled data in the same column $(P=0.25$ for layers in central retina; $P=0.125$ for periphery outer and inner nuclear layers, ONL and INL; $P=0.063$ for periphery OPL and IPL, one-sample Wilcoxon signed paired ranks test). Western blot analysis of retinal opsins (Figure 3C) showed a significant reduction of rhodopsin expression $(P=0.017$, unpaired $t$-test) but not of cone-opsins $(P=0.34$, unpaired $t$-test), providing additional support to the notion that the initial damage caused by DR in the outer retina primary affects rods but not cones. In order to test whether the damage of the neural

TABLE 2 | Blood glucose concentration.

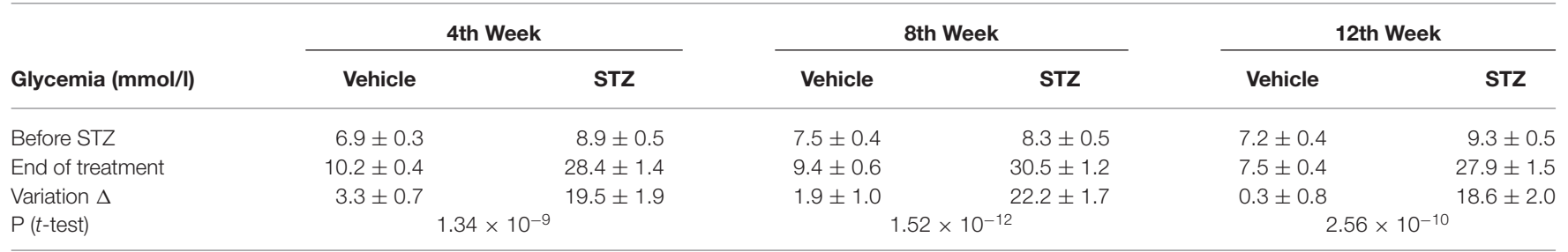

Glycaemia levels in vehicle- and STZ-injected mice used in the study. Data are expressed as average \pm SEM. Statistical comparisons using independent two-sample t-test. 

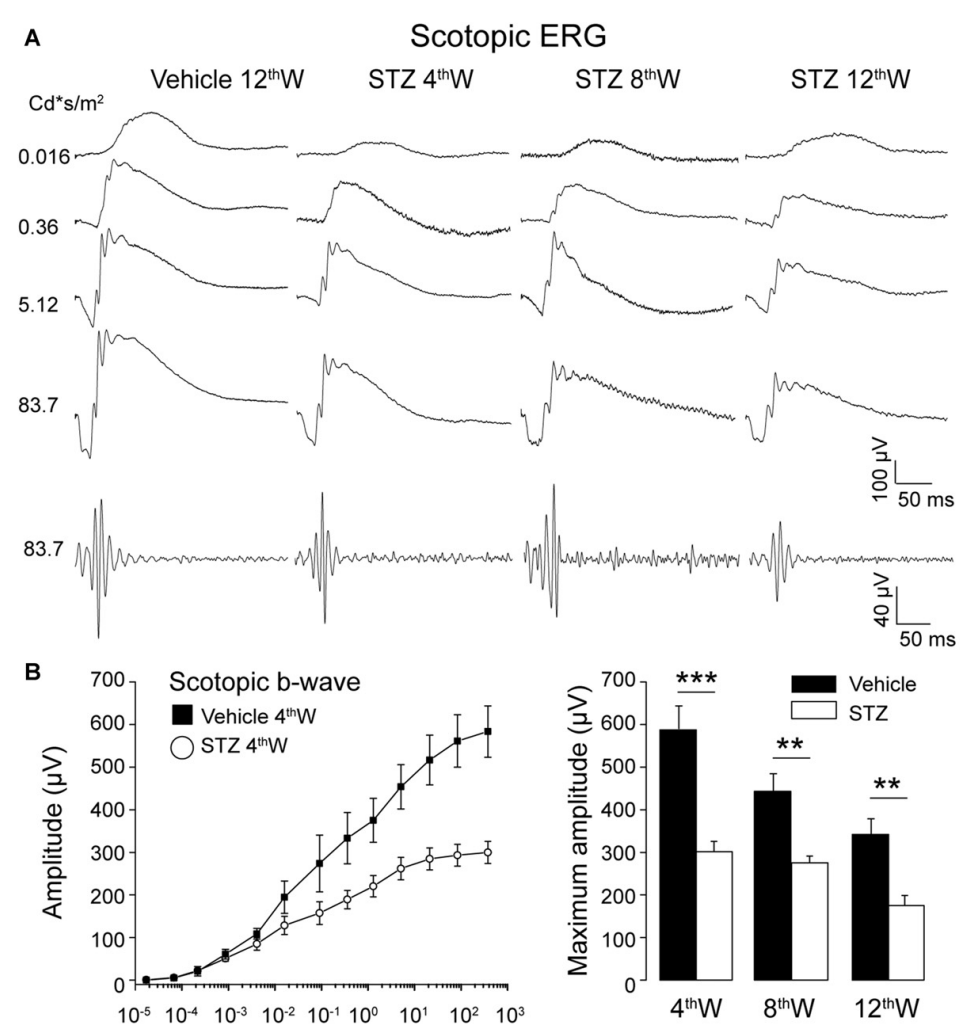

Flash intensity $\left(\mathrm{cd}^{*} \mathrm{~s} / \mathrm{m}^{2}\right)$

C
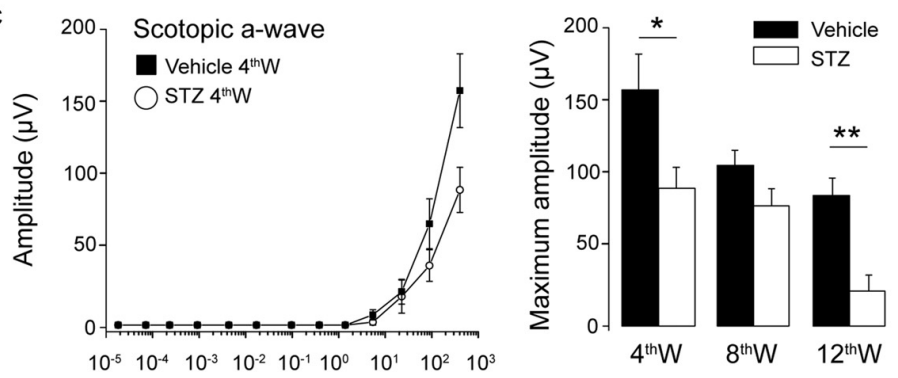

Flash intensity $\left(\mathrm{cd}^{*} \mathrm{~s} / \mathrm{m}^{2}\right)$
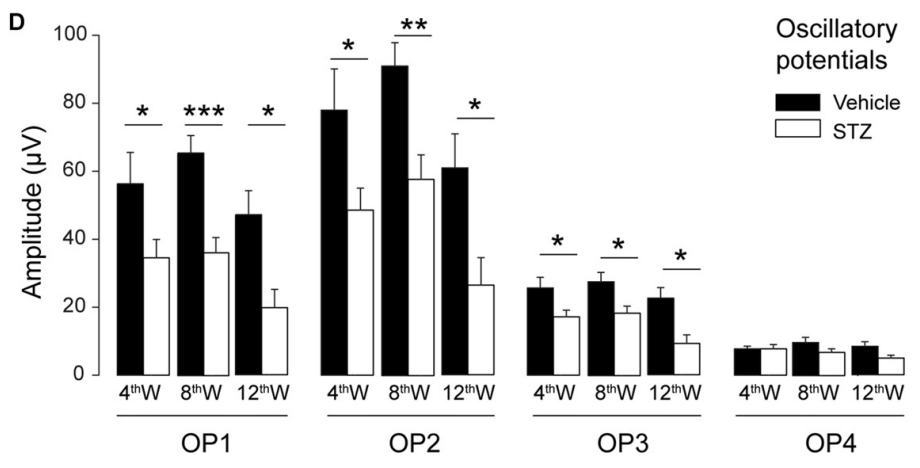

FIGURE 1 | Early impairment of outer and inner retinal function in hyperglycemic mice. (A) Representative scotopic flash electroretinogram (ERG) responses from control and hyperglycemic mice 4, 8, 12 weeks after injection. Bottom traces: OPs filtered from the ERG response to the brightest flash. (B,C) Left: scotopic b-wave (B) and a-wave (C) amplitude as a function of flash intensity from 4 weeks vehicle- and STZ-injected mice. Right histograms: maximum b-wave (B) and a-wave (C) amplitude measured in response to the brightest flash $\left(377 \mathrm{~cd}^{*} \mathrm{~s} / \mathrm{m}^{2}\right)$ for control and hyperglycemic mice. (D) Average amplitude of oscillatory potentials $(\mathrm{OP} 1 \div \mathrm{OP} 4)$ extracted from ERG response to the brightest flash $\left(377 \mathrm{~cd} * \mathrm{~s} / \mathrm{m}^{2}\right)$. Values expressed as average $\pm \mathrm{SEM}$. Statistical analysis $(t$-test $) * P<0.05, * * P<$ $0.01,{ }^{* * * *} P<0.001$. Number of vehicle- vs. STS-injected animals: 4 th week: $N=7$ vs. 13 . 8 th week: $N=6$ vs. $9 ; 12$ th week: $N=6$ vs. 7 . 

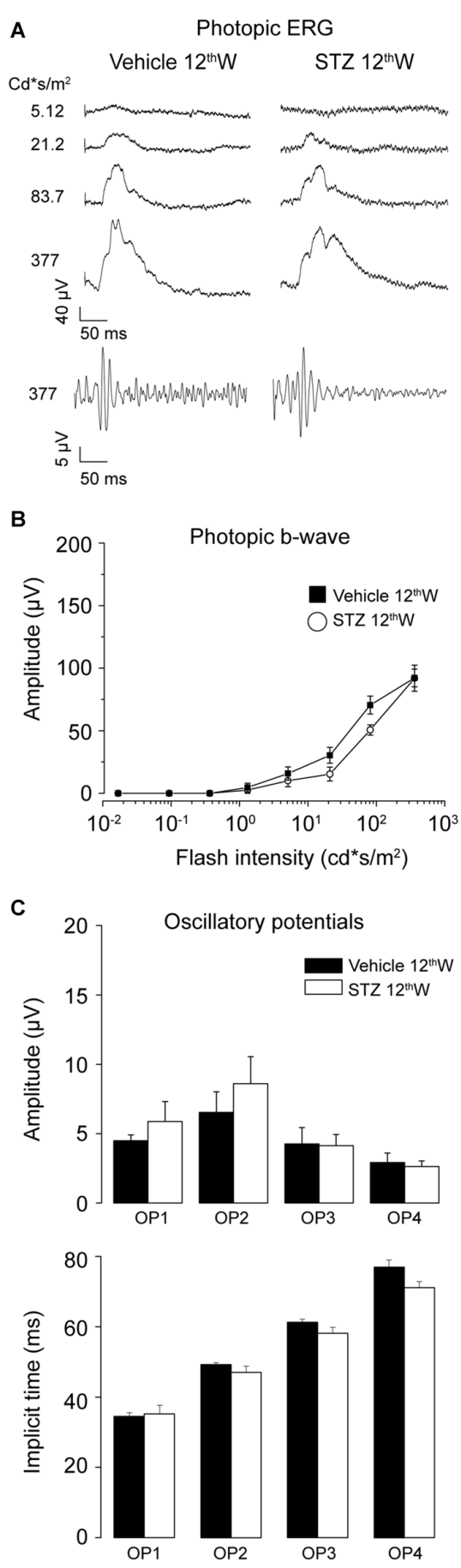

FIGURE 2 | Photopic ERG is not altered in hyperglycemic mice. (A) Representative photopic flash ERG responses from control and hyperglycemic mice 12 weeks after injection. Bottom traces: OPs extracted from the ERG response to the brightest flash. (B) Left: photopic b-wave amplitude as a function of delivered flash intensity for vehicle-and STZ-injected mice, 12 weeks after injection. (C) Average amplitude (top) and implicit time (bottom) of oscillatory potentials (OP1 - OP4) extracted from ERG response to the brightest flash $\left(377 \mathrm{~cd} * \mathrm{~s} / \mathrm{m}^{2}\right)$. Values expressed as average $\pm \mathrm{SEM}$. Vehicle-injected $N=6$, STZ, -injected $N=7$ animals. Statistical analysis of vehicle vs. diabetic mice ( $t$-test). Amplitude OP1-OP4: $P=0.34 ; 0.41 ; 0.94$; 0.75. Implicit Time: OP1-OP4 : $P=0.78 ; 0.26 ; 0.12 ; 0.04$. retina is correlated with vascular changes we also examined morphology of retinal blood vessels (Figure 4). Area (Figure 4B) and complexity of the vessels (Figure 4C) was determined for each of the three vascular plexa (see "Materials and Methods" Section).

The vascular area in each plexus was similar in control and diabetic animals (Figure 4B; for 4, 8 and 12 week respectively; deep plexus: $P=0.14 ; 0.54 ; 0.11$; intermediate plexus: $P=0.10$; 0.15 ; 0.67 ; superficial plexus: $P=0.33 ; 0.21 ; 0.26)$. Because in the time frame of 8-12 months control animals had similar blood vessels complexity $(P=0.75$, one-way ANOVA) data were pooled. The complexity of deep plexus vessels, supplying photoreceptors and bipolar cells, was significantly reduced in diabetic mice only 12 weeks post-injection (Figure 4C). In addition, no signs of neovascularization were detected throughout the period of observation. These results suggest that the damage to the neural retina in the early stages of DR cannot be attributed to a vascular injury.

We then investigated whether rod photoreceptors die by apoptosis, as reported for retinal ganglion cells (Barber et al., 1998; Park et al., 2003; Martin et al., 2004). Surprisingly, hardly any sign of apoptosis was detected in STZ-injected mice within the time frame of our analysis. Representative retinal sections stained for apoptotic cells with TUNEL (Figures 5A,B, 12 weeks after injection) show only rare apoptotic figures in both diabetic and control retinas. Furthermore, expression of activated Caspase-3 (Figure 5C) was not increased in diabetic mice with respect to control ( 4 weeks: $P=0.54$; 8 weeks: $P=0.46$; 12 weeks: $P=0.29$ ). We also found that in contrast to other forms of retinal degenerations, such as retinitis pigmentosa (Gargini et al., 2007), Müller glia was not activated (Figure 5D, 12 weeks). Together, these data suggest that rod photoreceptors death does not involve apoptosis in the early stage of STZ-induced DR. A possible alternative pathway leading to rod degeneration in DR is thus the dysregulation of autophagic flow.

We thus monitored three markers of autophagy: Beclin-1, Atg5 and the microtubule-associated protein 1A/1B-light chain 3A (LC3A) that play critical roles in the nucleation, expansion and conjugation steps of autophagosome formation, respectively. LC3A undergoes cleavage and lipidation to LC3A-II (Larsen and Sulzer, 2002; Mehrpour et al., 2010) becoming a component of the mature autophagosome (Mizushima and Yoshimori, 2007). In control retina, LC3A (Figure 6A, top panel) was mainly present in photoreceptor outer segments, normally involved in the process of the discs shedding and renewal (Remé and Sulser, 1977; Remé et al., 1986). In diabetic mice, LC3A (Figure 6A, top panels) labeling was stronger in photoreceptors as well as in synaptic layers compared to control retinas. In parallel, the architecture of photoreceptor synaptic terminals and rod bipolar cell dendrites was progressively disrupted (Figure 6A, bottom panels). In parallel to changes observed in synaptic layers, LC3A labeling increases also in the ganglion cell layer, indicating increased autophagic activity of retinal ganglion cells and/or displaced amacrine cells. LC3A assumed a punctuate distribution at the level of OPL in diabetic mice (Figure 6B), next to photoreceptors synaptic terminals indicated by the presynaptic protein PSD95. 


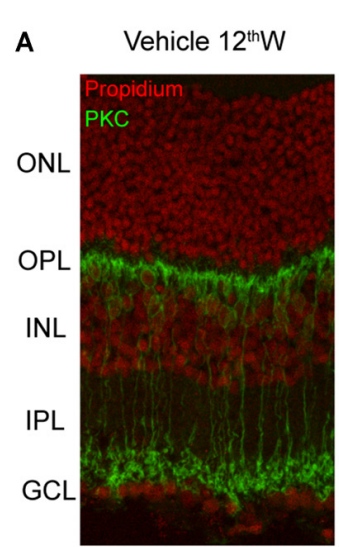

B

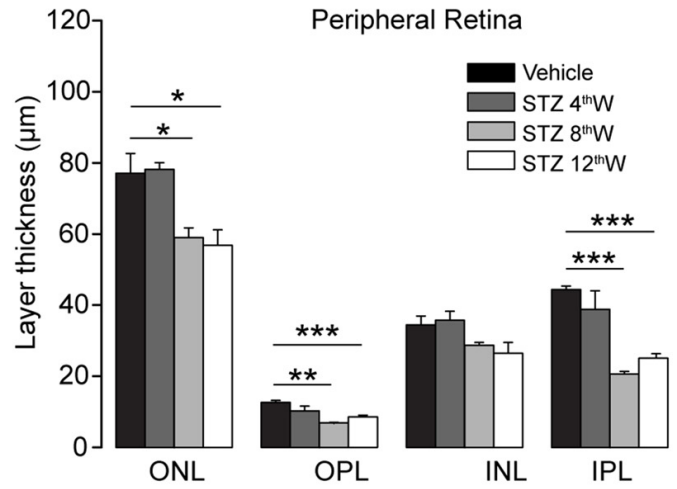

C

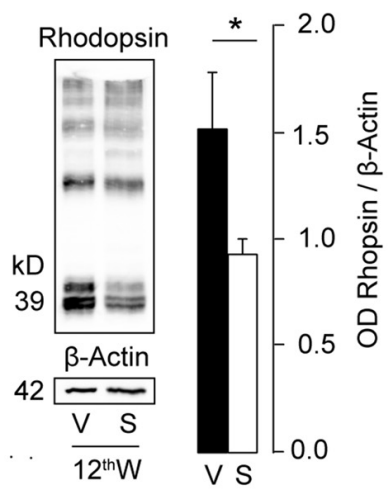

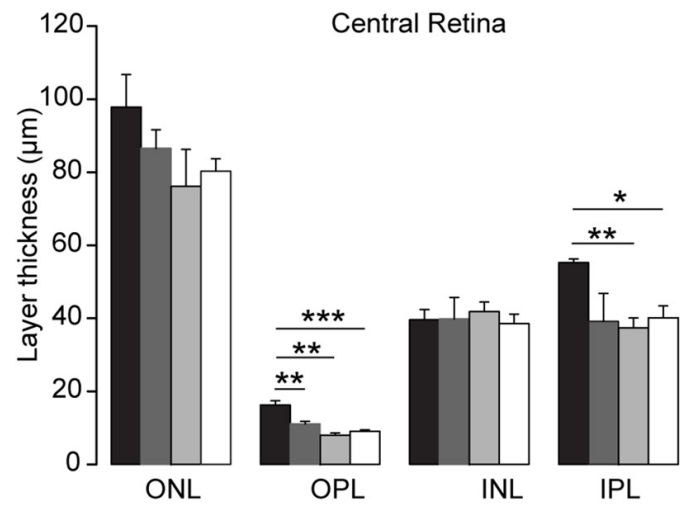

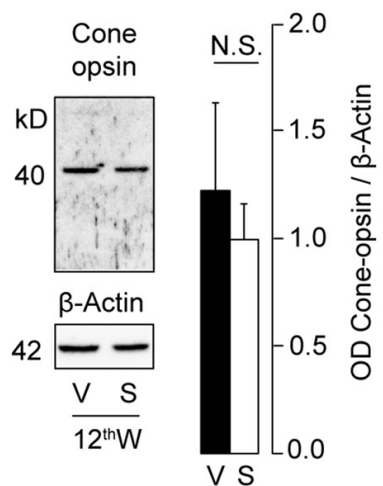

FIGURE 3 | Reduction of photoreceptors and retinal synaptic layers in hyperglycemic mice. (A) Retinal sections from vehicle-injected and STZ-injected mice at 4, 8 and 12 weeks after induction of hyperglycemia. Nuclear layers (red) and rod bipolar cells (green) are labeled. (B) Retinal layer thickness in control and hyperglycemic mice. Top histograms: thickness in the peripheral retina for nuclear (ONL, INL) and synaptic layers (OPL, IPL). Bottom histograms: layer thickness in the central retina for the same regions. $N=3$ animals for each condition. (C) Western blot analysis of rhodopsin and cone-opsin content in retinas of control and hyperglycemic mice, collected 12 weeks after injection. Left images: example western blots. Right histograms: optical density ratio opsin/ $\beta$-actin in control and hyperglycemic mice. $N=6$ animals for each condition. Values expressed as average \pm SEM. Statistical analysis $(t$-test $){ }^{*} P<0.05$, ${ }^{* *} P<0.01,{ }^{* * *} P<0.001$.

Retinal levels for Beclin-1, Atg5 and LC3A at each temporal point were investigated in both vehicle- and STZ-injected mice (Figure 6C). Quantification of these proteins (Figures 6D-F) revealed an increase in both Atg5 and Beclin-1 in the retinas of diabetic mice compared to control $(P=0.03$ and 0.006 , respectively, 12 weeks after diabetes induction, $t$-test). Quantification of the fraction of LC3A-II over total LC3A (Figure 6F) showed a tendency to increase in diabetic retinas but not to a significant level, possibly due to the presence of a strong physiological autophagic flux within photoreceptor outer segments. 
A
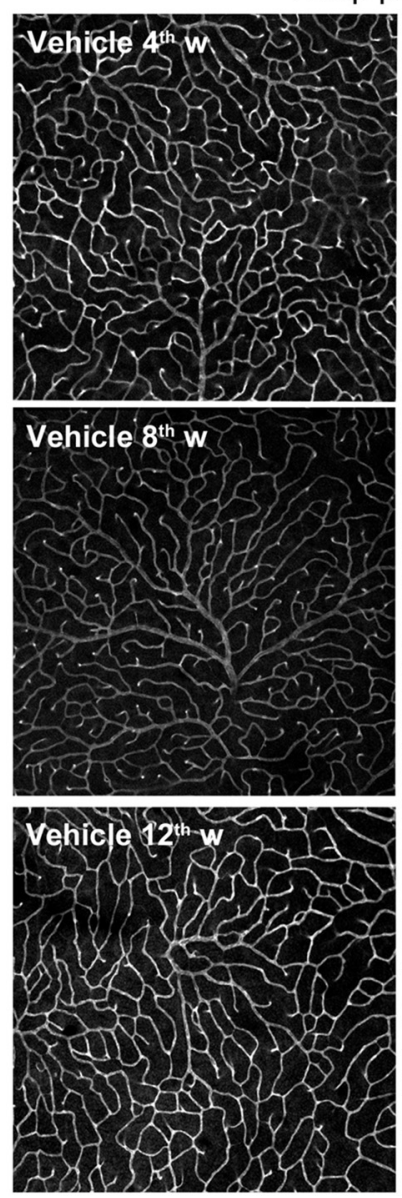

B
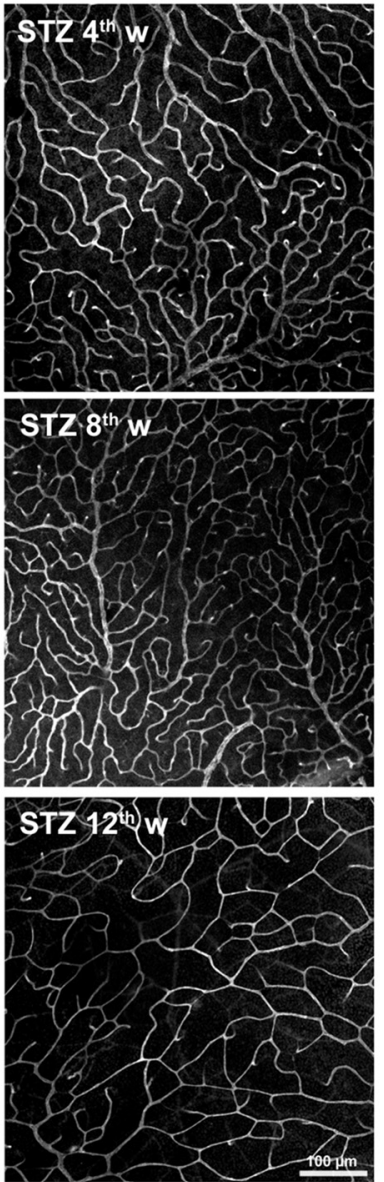
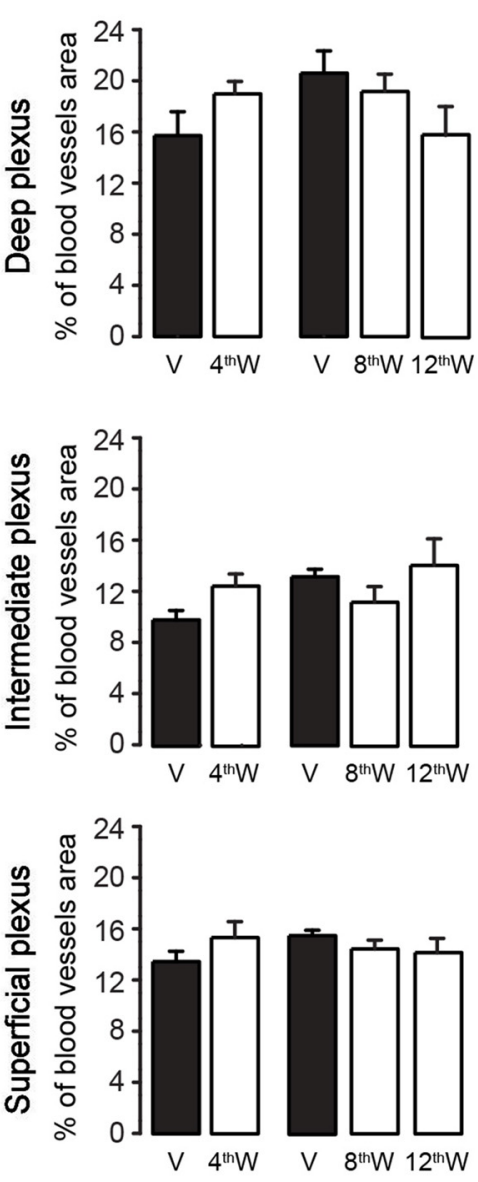

C Vascular complexity
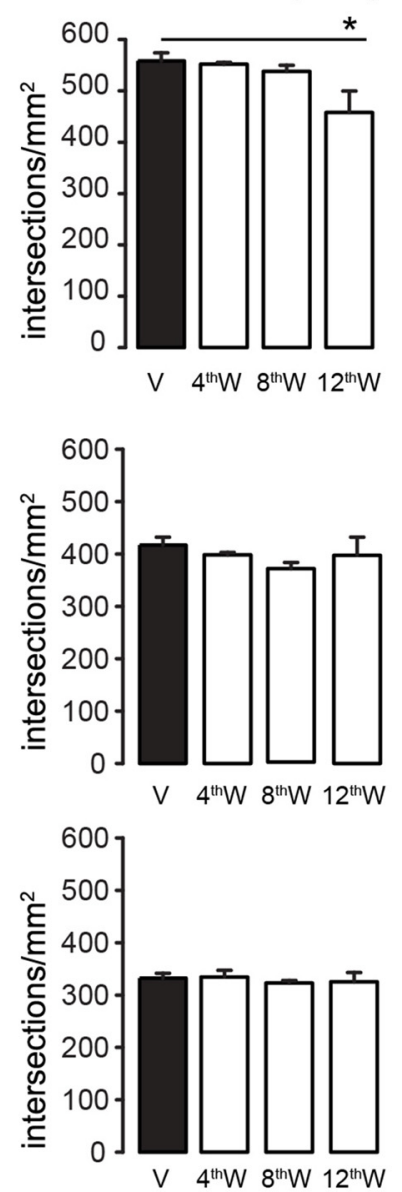

FIGURE 4 | Retinal blood vessels area and complexity. (A) Representative images of retinal blood vessel in the deep plexus in vehicle-injected and STZ-injected mice at 4, 8 and 12 weeks from injection. Blood vessels were stained with Lectin. (B) Quantification of relative vascular area, expressed as percentage of area in the plexus taken by blood vessels, within the deep (top plot) intermediate (middle) and superficial (bottom) plexa. (C) Quantification of vascular complexity, expressed as number of intersections between blood vessels per $\mathrm{mm}^{2}$, within the deep (top plot), intermediate (middle) and superficial (bottom) plexa. Values expressed as average \pm SEM. Statistical analysis (t-test) ${ }^{*} P<0.05$. Number of vehicle- vs. STZ-injected animals 4 th week: $N=3$ vs. $5 ; 8$ th week: $N=4$ vs. 5 ;

12th week: $N=3$ vs. 6 .

\section{DISCUSSION}

This study examined the electrophysiological, morphological and biochemical changes occurring in the mouse retina as a result of STZ-induced diabetes. Overall, our results show that one of the earliest signs of the disease is a selective alteration of the rod system, while the cone pathway is largely spared. Rods thus appear to be particularly vulnerable to the effects of diabetes, possibly due to their high metabolic demands (Demontis et al., 1997). Our results showing reduction of scotopic a- and b- wave are in agreement with data in diabetic rat models previously reported by other authors (Shirao and Kawasaki, 1998; Li et al., 2002; Phipps et al., 2004, 2006; Aung et al., 2013). We have extended the electrophysiological analysis to the OP component of ERG to show that it is altered in diabetic mice. Rod dysfunction is correlated with thinning of synaptic layers and altered morphology of second order neurons, in accordance with evidence found in a genetic mouse model (Ins $2^{\text {Akita }}$ ) of DR (Hombrebueno et al., 2014). Within the time frame of our analysis, vascular permeability was neither significantly altered nor did we observe any signs of neovascularization. Complexity of blood vessels supplying photoreceptors and bipolar cells is significantly reduced only 12 weeks from diabetes induction, well after the first signs of functional and morphological alterations.

No strong evidence for apoptosis was observed in the mouse retina over the duration of diabetes examined here. Our results are consistent with results in two rat models of diabetes (Énzsöly et al., 2014). Although one cannot exclude the possibility of undetected short lasting apoptotic events, functional and morphological data point to a continuous progression of the damage during the first 12 weeks after STZ injection. Conversely, a substantial increase of autophagic 

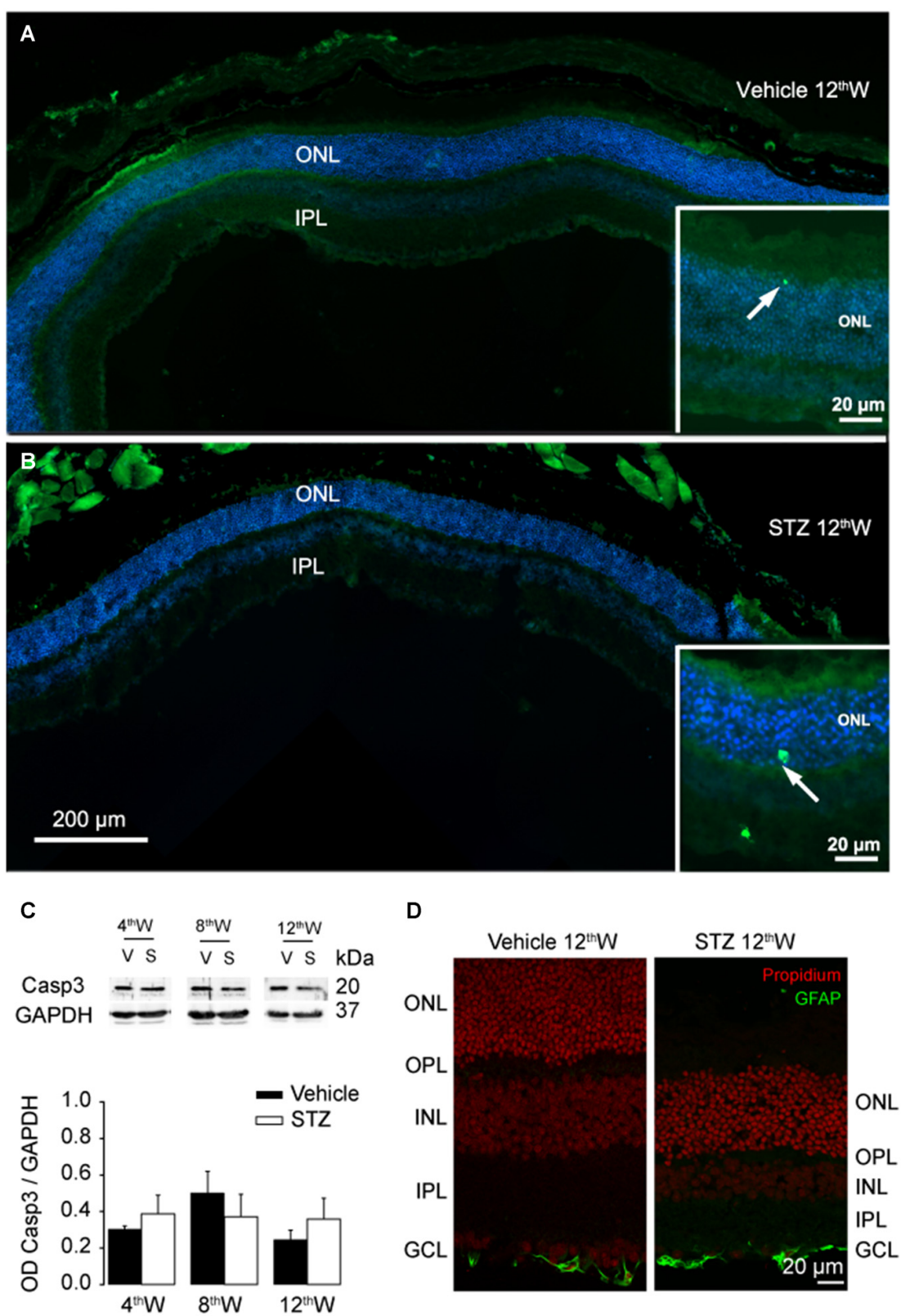

FIGURE 5 | Lack of apoptosis activation in photoreceptors of hyperglycemic mice. (A,B) Representative retinal sections from control and hyperglycemic mice, 12 weeks after injection. Apoptotic cells (green) labeled with TUNEL staining, cellular nuclei labeled with Hoechst (blue). Insets: magnification of the area where sporadic apoptotic cells were found. (C) Top: representative western blots labeled against the activated form of the apoptosis effector Caspase-3 and the control protein GAPDH. Bottom histograms: average ratio of the optical density of Caspase-3 and GAPDH after 4, 8, 12 weeks from injection. Values expressed as average \pm SEM. Statistical analysis in vehicle vs. diabetic mice ( $t$-test): 4 th week: $P=0.54$; 8th week: $P=0.46 ; 12$ th week: $P=0.29$. $N=6$ animals per each condition.

(D) Retinal sections from control and hyperglycemic mice 12 weeks after injection. Cellular nuclei are labeled with propidium iodide (red). Activated Müller glia was labeled with anti-GFAP antibody (green).

activity was shown in diabetic retinas using a variety of tests. Autophagy is generally regarded as a survival mechanism, and its deregulation has been linked to non-apoptotic cell death (Mehrpour et al., 2010; Nikoletopoulou et al., 2015). Here, we observe an increased expression of autophagic markers and in particular the staining of LC3A increases mainly in the OPL where an impairment of both pre- and post-synaptic proteins is apparent. Down-regulation of photoreceptor presynaptic proteins has been observed in other rodent models of diabetes (Park et al., 2003; Ozawa et al., 2011; Hombrebueno et al., 2014) as well as in patients with mild DR (Varga et al., 2015). Multiple evidence from cultured retinal explants suggests that high glucose exposure is sufficient to cause altered expression of key synaptic components such as vesicular GABA transporter 

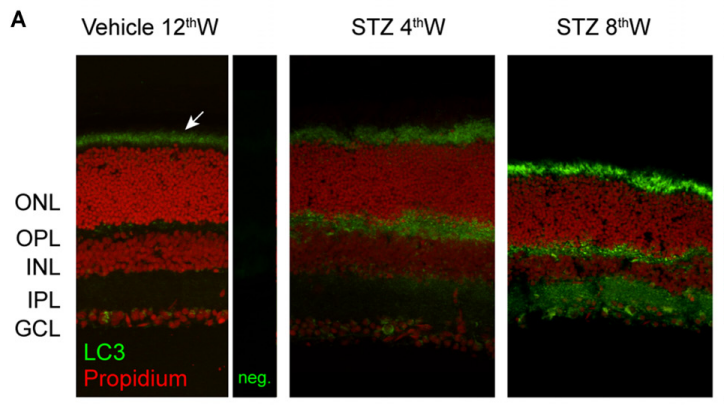

STZ $12^{\text {th } W}$
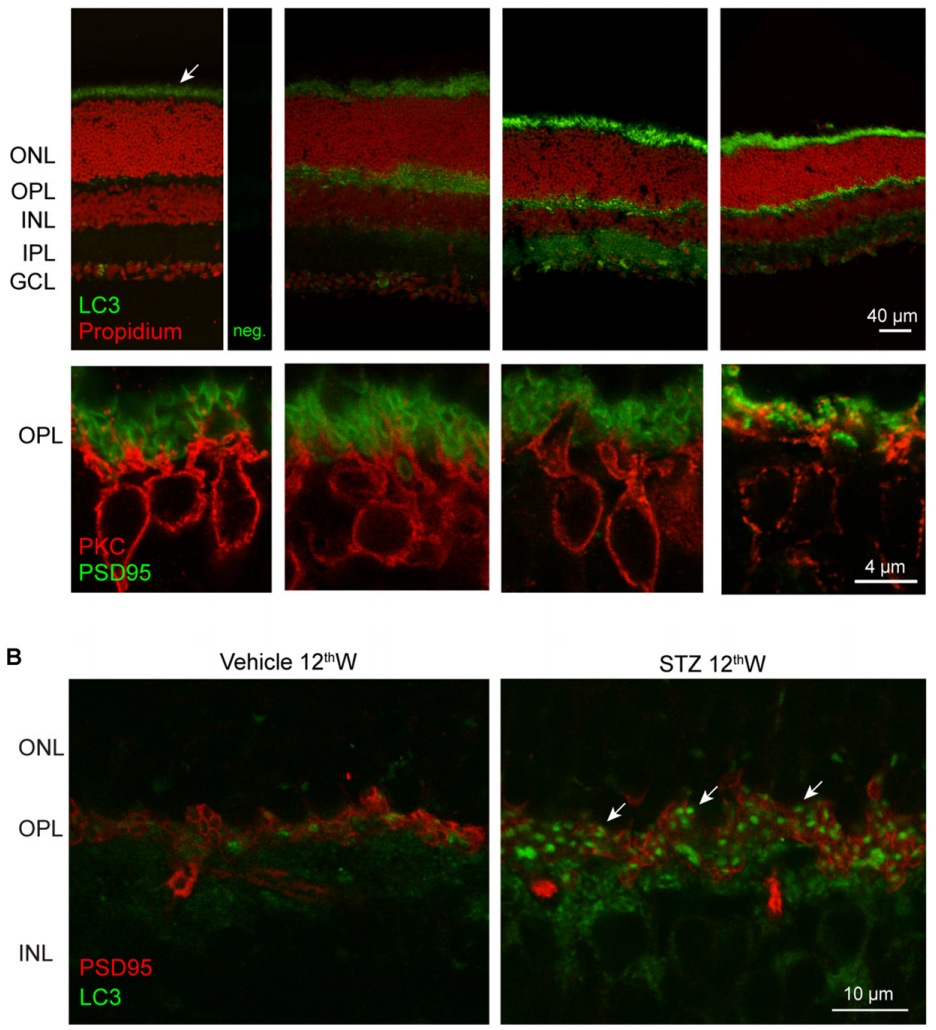

C

D $\quad$ Vehicle $\square$ STZ
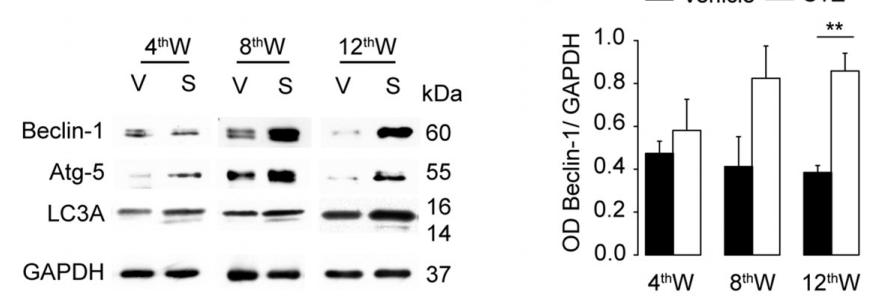

E
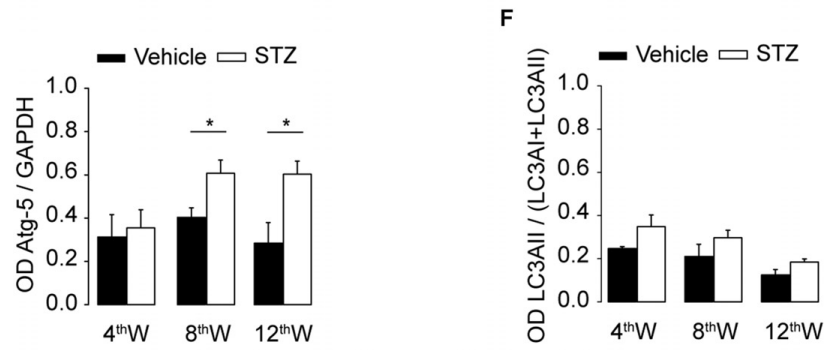

FIGURE 6 | Upregulation of autophagic proteins in hyperglycemic mice. (A) Top row: LC3 localization (green) in control and in STZ-injected retinas, nuclei in red (propidium iodide). Top left panel shows control retina next to negative control labeling with secondary antibody (neg.). The arrow indicates autophagy normally taking place during photoreceptor outer segments renewal. Bottom row: photoreceptor presynaptic protein PSD95 (green) and rod bipolar cells (red) labeled at the level of OPL. (B) Double-staining with PSD95 (red) and LC3 (green) at the level of OPL in retinas from control and diabetic mice, 12 weeks from injection. Arrows indicate in STZ-treated retina the punctate accumulation of LC3 at the level of OPL. (C) Representative western blot experiments. Autophagic markers Beclin-1, Atg-5 and light chain 3A (LC3A) as well as control GAPDH were assayed at 4, 8 and 12 weeks from injection. (D,E) Quantification of the average ratio between autophagic proteins Beclin-1 (D) Atg-5 (E) and the control protein GAPDH. (F) Quantification of the fraction of LC3All (activated isoform) over total LC3A content at 4,8 and 12 weeks from injections. Values expressed as average \pm SEM. Statistical analysis $\left(t\right.$-test) ${ }^{*} P<0.05,{ }^{* *} P<0.01,{ }^{* * *} P<0.001$. $N=6$ animals for each condition. 
(Baptista et al., 2015), purinergic receptors (Vindeirinho et al., 2013) and extracellular ATP levels (Costa et al., 2009), thus making the synaptic layers of the retina particularly prone to alterations occurring in early phases of DR. We therefore propose that the synaptic contacts in the outer retina undergo increased autophagy in response to diabetes. Up-regulation of autophagy occurs within the same time frame of outer retina damage and thus possibly represents the process leading to photoreceptor death in the early phase of DR. Recently other studies reported the up-regulation of autophagic pathway in the progression of neurodegenerative diseases such as glaucoma (Munemasa and Kitaoka, 2015; Wei et al., 2015) and suggested that the decrease of the autophagic pathway triggers degeneration of the retinal pigment epithelium (RPE; Yao et al., 2015).

It is perhaps interesting to note that deregulation of autophagy in diabetic retinas affects rods, a type of visual cells in which this process is particularly active in physiological conditions because of outer segment disc turnover and shedding (Remé et al., 1986). The identification of dysregulated autophagy affecting retinal neurons and their synaptic connections in the early stage of DR may open interesting perspectives for novel therapeutic strategies targeting key proteins of the autophagic pathway to restore the normal condition of this physiological process. Recent evidence in cell cultures

\section{REFERENCES}

Abu-El-Asrar, A. M., Dralands, L., Missotten, L., Al-Jadaan, I. A., and Geboes, K. (2004). Expression of apoptosis markers in the retinas of human subjects with diabetes. Invest. Ophthalmol. Vis. Sci. 45, 2760-2766. doi: 10.1167/iovs.03-1392

Antonetti, D. A., Barber, A. J., Bronson, S. K., Freeman, W. M., Gardner, T. W., Jefferson, L. S., et al. (2006). Diabetic retinopathy: seeing beyond glucoseinduced microvascular disease. Diabetes 55, 2401-2411. doi: 10.2337/db051635

Aung, M. H., Kim, M. K., Olson, D. E., Thule, P. M., and Pardue, M. T. (2013). Early visual deficits in streptozotocin-induced diabetic long evans rats. Invest. Ophthalmol. Vis. Sci. 54, 1370-1377. doi: 10.1167/iovs.12-10927

Baptista, F. I., Castilho, Á. F., Gaspar, J. M., Liberal, J. T., Aveleira, C. A., and Ambrósio, A. F. (2015). Long-term exposure to high glucose increases the content of several exocytotic proteins and of vesicular GABA transporter in cultured retinal neural cells. Neurosci. Lett. 602, 56-61. doi: 10.1016/j.neulet. 2015.06.044

Barber, A. J., Antonetti, D. A., Kern, T. S., Reiter, C. E. N., Soans, R. S., Krady, J. K., et al. (2005). The Ins2Akita mouse as a model of early retinal complications in diabetes. Invest. Ophthalmol. Vis. Sci. 46, 2210-2218. doi: 10.1167/iovs.04-1340

Barber, A. J., Lieth, E., Khin, S. A., Antonetti, D. A., Buchanan, A. G., and Gardner, T. W. (1998). Neural apoptosis in the retina during experimental and human diabetes. Early onset and effect of insulin. J. Clin. Invest. 102, 783-791. doi: 10. $1172 /$ jci2 225

Barone, I., Novelli, E., Piano, I., Gargini, C., and Strettoi, E. (2012). Environmental enrichment extends photoreceptor survival and visual function in a mouse model of retinitis pigmentosa. PLoS One 7:e50726. doi: 10.1371/journal.pone. 0050726

Bearse, M. A., Adams, A. J., Han, Y., Schneck, M. E., Ng, J., Bronson-Castain, K., et al. (2006). A multifocal electroretinogram model predicting the development of diabetic retinopathy. Prog. Retin. Eye Res. 25, 425-448. doi: 10.1016/j. preteyeres.2006.07.001

Blake, R., and Trounce, I. A. (2014). Mitochondrial dysfunction and complications associated with diabetes. Biochim. Biophys. Acta 1840, 1404-1412. doi: 10. 1016/j.bbagen.2013.11.007 supports this idea by showing that inhibition of autophagy may protect retinal cells from high glucose stress (Shi et al., 2015).

Collectively, our data show for the first time that, in addition to known apoptotic processes, autophagic pathway is probably involved in neuronal retinal degeneration. The present results may be useful for the exploration of new cell death pathways involved in the progression of DR and new targets could be evaluated in order to protect retinal neurons from damage.

\section{AUTHOR CONTRIBUTIONS}

IP, EN, LDS performed the experiments and analyzed data. IP, LDS, ES, LC designed the experiments, contributed to discussion. LDS, CG, LC, IP wrote the manuscript.

\section{ACKNOWLEDGMENTS}

The current study was supported by the Italian ministry of university and research (MIUR, PRIN Project 2010-2011 to CG) and by Velux Foundation (grant 691 to ES). The authors want to thank Dr. Antonella Caputo for her contribution in the initial experiments of this work.

Bolte, S., and Cordelières, F. P. (2006). A guided tour into subcellular colocalization analysis in light microscopy. J. Microsc. 224, 213-232. doi: 10 1111/j.1365-2818.2006.01706.x

Cheung, N., Mitchell, P., and Wong, T. Y. (2010). Diabetic retinopathy. Lancet 376, 124-136. doi: 10.1016/S0140-6736(09)62124-3

Costa, G., Pereira, T., Neto, A. M., Cristóvão, A. J., Ambrósio, A. F., and Santos, P. F. (2009). High glucose changes extracellular adenosine triphosphate levels in rat retinal cultures. J. Neurosci. Res. 87, 1375-1380. doi: 10.1002/jnr.21956

Della Santina, L., Piano, I., Cangiano, L., Caputo, A., Ludwig, A., Cervetto, L., et al. (2012). Processing of retinal signals in normal and HCN deficient mice. PLoS One 7:e29812. doi: 10.1371/journal.pone.0029812

Demontis, G. C., Longoni, B., Gargini, C., and Cervetto, L. (1997). The energetic cost of photoreception in retinal rods of mammals. Arch. Ital. Biol. 135, 95-109.

Énzsöly, A., Szabó, A., Kántor, O., Dávid, C., Szalay, P., Szabó, K., et al. (2014). Pathologic alterations of the outer retina in streptozotocin-induced diabetes. Invest. Ophthalmol. Vis. Sci. 55, 3686-3699. doi: 10.1167/iovs.13-13562

Gargini, C., Terzibasi, E., Mazzoni, F., and Strettoi, E. (2007). Retinal organization in the retinal degeneration 10 (rd10) mutant mouse: a morphological and ERG study. J. Comp. Neurol. 500, 222-238. doi: 10.1002/cne.21144

Gaucher, D., Chiappore, J.-A., Pâques, M., Simonutti, M., Boitard, C., Sahel, J. A., et al. (2007). Microglial changes occur without neural cell death in diabetic retinopathy. Vision Res. 47, 612-623. doi: 10.1016/j.visres.2006.11.017

Gonzalez, C. D., Lee, M.-S., Marchetti, P., Pietropaolo, M., Towns, R., Vaccaro, M. I., et al. (2011). The emerging role of autophagy in the pathophysiology of diabetes mellitus. Autophagy 7, 2-11. doi: 10.4161/auto.7.1.13044

Hancock, H. A., and Kraft, T. W. (2004). Oscillatory potential analysis and ERGs of normal and diabetic rats. Invest. Ophthalmol. Vis. Sci. 45, 1002-1008. doi: 10. 1167/iovs.03-1080

Hombrebueno, J. R., Chen, M., Penalva, R. G., and Xu, H. (2014). Loss of synaptic connectivity, particularly in second order neurons is a key feature of diabetic retinal neuropathy in the Ins2Akita mouse. PLoS One 9:e97970. doi: 10. 1371/journal.pone.0097970

Jo, D. H., Cho, C. S., Kim, J. H., Jun, H. O., and Kim, J. H. (2013). Animal models of diabetic retinopathy: doors to investigate pathogenesis and potential therapeutics. J. Biomed. Sci. 20:38. doi: 10.1186/1423-0127-20-38 
Johnston, J. A., Ward, C. L., and Kopito, R. R. (1998). Aggresomes: a cellular response to misfolded proteins. J. Cell Biol. 143, 1883-1898. doi: 10.1083/jcb. 143.7.1883

Kaul, K., Tarr, J. M., Ahmad, S. I., Kohner, E. M., and Chibber, R. (2013). "Introduction to diabetes mellitus," in Diabetes Advances in Experimental Medicine and Biology, ed. S. I. Ahmad (New York, NY: Springer New York), $1-11$.

Larsen, K. E., and Sulzer, D. (2002). Autophagy in neurons: a review. Histol. Histopathol. 17, 897-908.

Lei, B., Yao, G., Zhang, K., Hofeldt, K. J., and Chang, B. (2006). Study of rodand cone-driven oscillatory potentials in mice. Invest. Ophthalmol. Vis. Sci. 47, 2732-2738. doi: 10.1167/iovs.05-1461

Li, Q., Zemel, E., Miller, B., and Perlman, I. (2002). Early retinal damage in experimental diabetes: electroretinographical and morphological observations. Exp. Eye Res. 74, 615-625. doi: 10.1006/exer.2002.1170

Martin, P. M., Roon, P., Van Ells, T. K., Ganapathy, V., and Smith, S. B. (2004). Death of retinal neurons in streptozotocin-induced diabetic mice. Invest. Ophthalmol. Vis. Sci. 45, 3330-3336. doi: 10.1167/iovs.04-0247

Mehrpour, M., Esclatine, A., Beau, I., and Codogno, P. (2010). Overview of macroautophagy regulation in mammalian cells. Cell Res. 20, 748-762. doi: 10. 1038/cr.2010.82

Mizushima, N., and Yoshimori, T. (2007). How to interpret LC3 immunoblotting. Autophagy 3, 542-545. doi: 10.4161/auto.4600

Munemasa, Y., and Kitaoka, Y. (2015). Autophagy in axonal degeneration in glaucomatous optic neuropathy. Prog. Retin. Eye Res. 47, 1-18. doi: 10.1016/j. preteyeres.2015.03.002

Nikoletopoulou, V., Papandreou, M.-E., and Tavernarakis, N. (2015). Autophagy in the physiology and pathology of the central nervous system. Cell Death Differ. 22, 398-407. doi: 10.1038/cdd.2014.204

Ozawa, Y., Kurihara, T., Sasaki, M., Ban, N., Yuki, K., Kubota, S., et al. (2011). Neural degeneration in the retina of the streptozotocin-induced type 1 diabetes model. Exp. Diabetes Res. 2011:108328. doi: 10.1155/2011/108328

Park, S. H., Park, J. W., Park, S. J., Kim, K. Y., Chung, J. W., Chun, M. H., et al. (2003). Apoptotic death of photoreceptors in the streptozotocin-induced diabetic rat retina. Diabetologia 46, 1260-1268. doi: 10.1007/s00125-0031177-6

Phipps, J. A., Fletcher, E. L., and Vingrys, A. J. (2004). Paired-flash identification of rod and cone dysfunction in the diabetic rat. Invest. Ophthalmol. Vis. Sci. 45, 4592-4600. doi: 10.1167/iovs.04-0842

Phipps, J. A., Yee, P., Fletcher, E. L., and Vingrys, A. J. (2006). Rod photoreceptor dysfunction in diabetes: activation, deactivation, and dark adaptation. Invest. Ophthalmol. Vis. Sci. 47, 3187-3194. doi: 10.1167/iovs.05-1493

Remé, C. E., and Sulser, M. (1977). Diurnal variation of autophagy in rod visual cells in the rat. Albrecht Von Graefes Arch. Klin. Exp. Ophthalmol. 203, 261-270. doi: $10.1007 / \mathrm{bf} 00409832$
Remé, C., Wirz-Justice, A., Rhyner, A., and Hofmann, S. (1986). Circadian rhythm in the light response of rat retinal disk-shedding and autophagy. Brain Res. 369, 356-360. doi: 10.1016/0006-8993(86)90550-0

Schindelin, J., Arganda-Carreras, I., Frise, E., Kaynig, V., Longair, M., Pietzsch, T., et al. (2012). Fiji: an open-source platform for biological-image analysis. Nat. Methods 9, 676-682. doi: 10.1038/nmeth.2019

Shi, H., Zhang, Z., Wang, X., Li, R., Hou, W., Bi, W., et al. (2015). Inhibition of autophagy induces IL- $1 \beta$ release from ARPE-19 cells via ROS mediated NLRP3 inflammasome activation under high glucose stress. Biochem. Biophys. Res. Commun. 463, 1071-1076. doi: 10.1016/j.bbrc.2015.06.060

Shirao, Y., and Kawasaki, K. (1998). Electrical responses from diabetic retina. Prog. Retin. Eye Res. 17, 59-76. doi: 10.1016/s1350-9462(97)00005-0

Varga, B. E., Gao, W., Laurik, K. L., Tátrai, E., Simó, M., Somfai, G. M., et al. (2015). Investigating tissue optical properties and texture descriptors of the retina in patients with multiple sclerosis. PLoS One 10:e0143711. doi: 10.1371/journal. pone. 0143711

Vindeirinho, J., Costa, G. N., Correia, M. B., Cavadas, C., and Santos, P. F. (2013). Effect of diabetes/hyperglycemia on the rat retinal adenosinergic system. PLoS One 8:e67499. doi: 10.1371/journal.pone.0067499

Wang, Z., Yadav, A. S., Leskova, W., and Harris, N. R. (2010). Attenuation of streptozotocin-induced microvascular changes in the mouse retina with the endothelin receptor A antagonist atrasentan. Exp. Eye Res. 91, 670-675. doi: 10. 1016/j.exer.2010.08.008

Wei, T., Kang, Q., Ma, B., Gao, S., Li, X., and Liu, Y. (2015). Activation of autophagy and paraptosis in retinal ganglion cells after retinal ischemia and reperfusion injury in rats. Exp. Ther. Med. 9, 476-482. doi: 10.3892/etm.2014. 2084

Yao, J., Jia, L., Khan, N., Lin, C., Mitter, S. K., Boulton, M. E., et al. (2015). Deletion of autophagy inducer RB1CC1 results in degeneration of the retinal pigment epithelium. Autophagy 11, 939-953. doi: 10.1080/15548627.2015.1041699

Zeng, X. X., Ng, Y. K., and Ling, E. A. (2000). Neuronal and microglial response in the retina of streptozotocin-induced diabetic rats. Vis. Neurosci. 17, 463-471. doi: $10.1017 /$ s0952523800173122

Conflict of Interest Statement: The authors declare that the research was conducted in the absence of any commercial or financial relationships that could be construed as a potential conflict of interest.

Copyright (C) 2016 Piano, Novelli, Della Santina, Strettoi, Cervetto and Gargini. This is an open-access article distributed under the terms of the Creative Commons Attribution License (CC BY). The use, distribution and reproduction in other forums is permitted, provided the original author(s) or licensor are credited and that the original publication in this journal is cited, in accordance with accepted academic practice. No use, distribution or reproduction is permitted which does not comply with these terms. 